\title{
Tight Junctions of the Neurovascular Unit
}

\author{
Natalie Hudson* and Matthew Campbell \\ Trinity College Dublin, Smurfit Institute of Genetics, Dublin, Ireland
}

The homeostatic balance of the brain and retina is maintained by the presence of the blood-brain and inner blood-retinal barrier (BBB/iBRB, respectively) which are highly specialized barriers. Endothelial cells forming the lining of these blood vessels are interconnected by the presence of tight junctions which form the BBB and iBRB. These tight junctions, formed of numerous interacting proteins, enable the entry of molecules into neural tissues while restricting the entry of harmful material such as anaphylatoxins, bacteria and viruses. If the tight junction complex becomes dysregulated due to changes in expression levels of one or more of the components, this can have detrimental effects leading to brain and retinal pathology.

Keywords: tight junction, neurovasculature, endothelial cells, blood brain barrier, inner blood-retinal barrier

\section{OPEN ACCESS}

Edited by:

Eleonora Vannini,

Institute of Neuroscience, National

Research Council (CNR), Italy

Reviewed by:

Miruna G. Ghinia-Tegla,

City College of New York (CUNY),

United States

Shinsuke Nakagawa,

Fukuoka University, Japan

*Correspondence:

Natalie Hudson

natalie.hudson@tcd.ie

Specialty section:

This article was submitted to

Molecular Signaling and Pathways,

a section of the journal

Frontiers in Molecular Neuroscience

Received: 03 August 2021

Accepted: 07 October 2021

Published: 19 November 2021

Citation:

Hudson N and Campbell M

(2021) Tight Junctions of the

Neurovascular Unit.

Front. Mol. Neurosci. 14:752781. doi: 10.3389/fnmol.2021.752781

\section{INTRODUCTION}

Vascular heterogeneity is essential for the diverse functions and roles arising across the vascular tree; and is of particularly great importance in the brain and retina. The microvasculature of the brain and the retina differs vastly to other vascular beds due to the presence of the bloodbrain (BBB) or inner blood-retinal barrier (iBRB) which are formed from endothelial cells that interconnect via highly specialized and enriched tight junctions that act as selective barriers (Abbott et al., 2006; Hudson and Campbell, 2019). The tight junctions help to regulate the entry of molecules and ions, from the blood into the tissue while restricting entry of potential harmful blood-borne components, including immune cells and pathogens (Abbott et al., 2006). In addition to the endothelial cells, the $\mathrm{BBB}$ and $\mathrm{iBRB}$ requires the presence of astrocytes, pericytes, microglia, Müller cells, and the basement membrane to help facilitate the barrier properties that are intrinsic within the brain and retina. The microenvironment needs to be stringently controlled to maintain homeostatic conditions, as dysfunction of junctional components can lead to numerous brain and retinal pathologies (as shown in Table 1).

\section{COMPOSITION OF THE NEUROVASCULAR UNIT}

The neurovascular unit (NVU) is comprised of numerous interacting cells that facilitate the formation, maintenance and functionality of both the $\mathrm{BBB} / \mathrm{iBRB}$. The presence of each cell type; astrocytes, pericytes, microglia and Müller cells, with innervation from neurones, are all required to maintain brain and retinal homeostasis. The endothelial cells that form the blood vessel lumen are surrounded by pericytes which are then ensheathed by astrocytic end-feet that forms a continuous layer with the basal lamina (Figure 1).

Astrocytes and Müller cells are the most common glial cells in the brain and retina, respectively. Both cells types have essential roles in maintaining tissue homeostasis (Abbott et al., 2006; 
TABLE 1 | Contribution of tight junction components to disease pathology.

\begin{tabular}{|c|c|}
\hline Tight junction component & Disease pathology \\
\hline Claudin-5 & $\begin{array}{l}\text { - EAE/MS: claudin-5 loss and remodeling during leukocyte transmigration } \\
\text { - RPE atrophy observed in response to claudin-5 downregulation (animal model of dry AMD) } \\
\text { - Decreased claudin-5 levels detected in post-mortem brains of individuals diagnosed with Schizophrenia } \\
\text { - Decreased claudin-5 levels found in Epilepsy } \\
\text { - Stroke } \\
\text { - Cold-induced model of traumatic brain injury (TBI) found decreased claudin-5 levels reduced edema and accelerated recovery } \\
\text { - Repetitive mild TBI found decreased claudin-5 levels in association with deposition of hyperphosphorylated tau leading to BBB } \\
\text { - dysfunction } \\
\text { - Claudin-5 knockdown exacerbates social defeat model of depression } \\
\text { - Claudin-5 mislocalization and increased expression in oxygen induced retinopathy (OIR) model }\end{array}$ \\
\hline Claudin-1 & $\begin{array}{l}\text { - Increased expression in stroke } \\
\text { - Decreased expression in Glioblastoma Multiforme } \\
\text { - Expression of claudin-1 reduces vascular leakage in model of EAE }\end{array}$ \\
\hline Claudin-3 & - Decreased expression observed in EAE and Glioblastoma Multiforme \\
\hline Occludin & $\begin{array}{l}\text { - Lower occludin levels observed in Multiple Sclerosis } \\
\text { - VEGF mediated phosphorylation of occludin in Diabetic Retinopathy leads to dysfunctional iBRB } \\
\text { - Alzheimer's disease found increased amyloid- } \beta \text { clearance into blood when claudin- } 5 \text { and occludin down-regulated }\end{array}$ \\
\hline Zonula Occludens (ZO-1) & - In Multiple Sclerosis lesions ZO-1 expression reduced leading to junctional instability \\
\hline LSR & - Downregulated in EAE/middle cerebral artery occlusion leading to junctional instability \\
\hline JAM-A & $\begin{array}{l}\text { - Loss of JAM-A leads to increased neutrophil transmigration } \\
\text { - Increased JAM-A expression correlates with increased monocyte migration in HIV-infected individuals }\end{array}$ \\
\hline JAM-C & - Down-regulation of JAM-C inhibits wet AMD patient macrophage adhesion to endothelial cells \\
\hline
\end{tabular}

Reichenbach and Bringmann, 2020). They are involved in (1) regulating ion and water transport due to influencing the expression and locality of influx and efflux transporters such as aquaporin-4, (2) microvascular permeability mediated by calcium signaling to the endothelium, (3) cell-cell communication via junctional components, (4) development and maintenance of the $\mathrm{BBB} / \mathrm{iBRB}$ as loss of astrocytic end-feet overage leads to an increased BBB permeability (Segarra et al., 2018), and (5) release and uptake of neurotrophic factors such as glutamate and vascular endothelial growth factor (VEGF). Dysfunction of astrocyte or Müller cell behavior can contribute to neuroinflammation due to pro-inflammatory cytokine release or tissue edema due to water retention leading to tissue swelling (Abbott et al., 2006).

The presence of pericytes in the NVU aids in microvessel stability and regulation of blood flow due to pericyte contractility and relaxation (Peppiatt et al., 2006; Hamilton et al., 2010; Lendahl et al., 2019). In contrast to other vascular tissue beds, the ratio of pericytes to endothelial cells with the CNS and retina is significantly higher, with 1 pericyte: 1 endothelial cell in the retina (Frank et al., 1990). Pericyte populations vary along the vasculature- differing in their morphology and alpha smooth muscle actin expression depending on their location. Pericytes and the endothelium are usually separated physically by the basement membrane although the two cell types can directly interact at peg-socket contact sites (Lendahl et al., 2019). Platelet-derived growth factor (PDGF) signaling recruits pericytes to the $\mathrm{BBB}$ and $\mathrm{iBRB}$ and if signaling becomes dysfunctional pericyte numbers are greatly reduced leading to increased barrier permeability and dysfunction, although this may become dispensable in adult mice (Armulik et al., 2010; Daneman et al., 2010b; Park et al., 2017). Pericytes also release factors, such as angiopoietin, that influence barrier properties by inducing tight junction protein expression (Hori et al., 2004).
Loss or dysfunction of pericytes has been linked to various neurodegenerative conditions including, Alzheimer's Disease, Amyotrophic lateral sclerosis (Lendahl et al., 2019) and Diabetic Retinopathy (Enge et al., 2002).

Monocyte-derived microglia are CNS-resident macrophages which become activated in response to any changes detected within their microenvironment, such as injury or inflammation. They continually undertake immune surveillance in the tissue they reside accounting for between 10 and $15 \%$ of the cell population (Perry et al., 2010; Ronaldson and Davis, 2020). Depending on the signaling pathway initiated microglia can become either pro-inflammatory (M1) or antiinflammatory (M2) which can influence barrier properties by either upregulation or downregulation of tight junction components in both the brain and retina. M1 microglia have been implicated in $\mathrm{BBB}$ dysfunction due to the release and secretion of cytokines and chemokines such as interleukin (IL)- $1 \beta$, IL-12 and tumor necrosis factor (TNF) $\alpha$, and CCL2 which can increase leukocyte extravasation. M2 microglia are believed to play a more protective role by controlling inflammation and resolving injury due to the release of cytokines, including IL-10 and transforming growth factor (TGF)- $\beta$ (Ronaldson and Davis, 2020).

In addition to microglia, the presence of perivascular macrophages aids in maintaining tissue health. Perivascular macrophages act as antigen-presenting cells phagocytosing potential harmful material to present to leukocytes and subsequently can regulate leukocyte transmigration due to releasing anti-inflammatory cytokines. The presence of perivascular macrophages at the $\mathrm{BBB}$ and $\mathrm{iBRB}$ can enhance barrier tightness (Lapenna et al., 2018). As observed with the other cell types found within the NVU changes in perivascular macrophage behavior and number can be a causative role in neurodegenerative disease pathogenesis. 
A

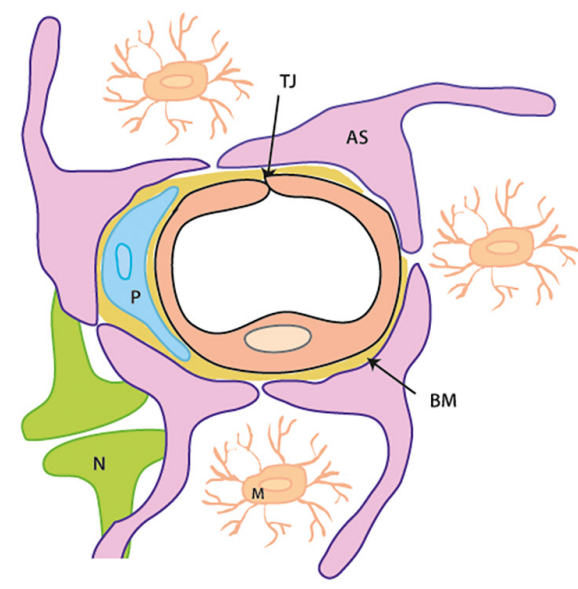

C

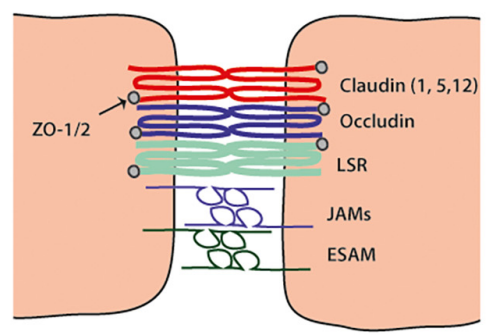

B

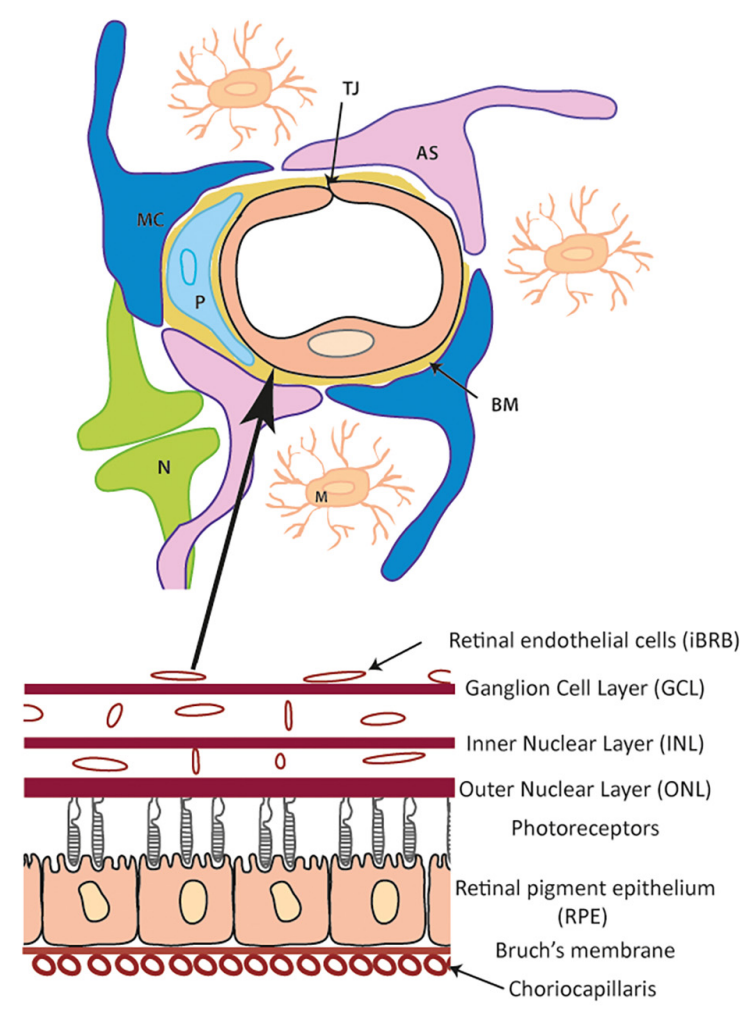

FIGURE 1 | Cellular and tight junction (TJ) protein composition of the blood- brain barrier (BBB) and inner blood-retinal barrier (iBRB). (A) Schematic of the blood brain barrier (BBB) neurovascular unit (NVU). A single endothelial cell (EC) forms the lumen of the blood vessels surrounded by a pericyte (P) and the basement membrane (BM) containing laminins, nidogens, collagen IV and heparin sulfate proteoglycans. Astrocytes (AS) end-feet ensheath the cell complex with neurone (N) and microglia (M) present in the microenvironment. (B) The iBRB is similar in composition to the BBB (as seen in $\mathbf{A}$ ) although pericytes $(\mathrm{P})$ are at a ratio of $1: 1$ with endothelial cells (EC) and Muller cell (MC) processes wrap around the blood vessels along with the astrocytes (AS). The iBRB is found in the retina from the ganglion cell layer (GCL) to the outer nuclear layer (ONL). (C) Schematic of tight junction proteins expressed that join the same endothelial cell or adjacent endothelial cells to one another. Claudin-5 is expressed most abundantly with contribution from claudin 1 and 12 (other family members shown to be expressed in other NVU cells). The TAMPs (occludin, tricellin) and LSR along with JAM family members (A-C and ESAM) constitute the additional transmembrane proteins. Zonula occludens (ZO) 1 and 2 are expressed cytoplasmic which can form a structural link to the actin cytoskeleton and associate with actin binding proteins.

Basement membrane proteins are essential in supporting role for the cells found within the NVU which are derived from astrocytes, pericytes and the endothelium. In the brain there are two basement membranes- the endothelial and parenchymal basement membrane which under healthy conditions are indistinguishable from one another, keeping a separation between the endothelium and neurones/glial cells. Laminin, collagen IV, nidogen and heparin sulfate proteoglycans (HSPGs) are proteins that form the basement membrane and other additional proteins, such as fibronectin, are also present although their expression is dependent on the developmental or physiologically state (Thomsen et al., 2017). Agrin and perlecan are the most abundant HSPGs which integrate within the collagen IV and laminin network assisting in integrity of the basement membrane as well as having the capability to bind growth factors. The interaction of the basement membrane and the NVU cells is mediated by integrin or dystroglycan receptors that maintain the cells in their correct location. For example, collagen IV of the basement membrane interacts with endothelial $\beta 1$ integrins. The expression of proteins found within the basement membrane network varies along the vascular beds. Laminin 411 and 511 are expressed in the endothelial basement membrane with low or patchy post-capillary venule expression of laminin 511 being preferential sites for leukocyte transmigration (Wu et al., 2009; Hallmann et al., 2020). Studies investigating neurodegenerative conditions, in conjunction with the use of transgenic animal models, have shown the important role that basement membrane proteins have in a functional and intact BBB (Thomsen et al., 2017). Many transgenic mice that lack the expression of a key basement membrane component are embryonic lethal, such as agrin or perlecan KO (Sarrazin et al., 2011) and collagen IV (Poschl et al., 2004), or die within a few weeks of birth, such as Lama2-/- mice (Miyagoe et al., 1997). Altered tight junction expression, resulting in a compromised $\mathrm{BBB}$, can arise due to the loss of basement membrane components as seen in mice lacking astrocytic laminin (Yao et al., 2014).

\section{TIGHT JUNCTIONS}

Tight junctions have been described to have "gate" (paracellular permeability) and "fence" (apical/basolateral polarity barrier) 
functions which are key to maintaining low endothelial permeability whilst providing a high transendothelial electrical resistance (Otani and Furuse, 2020). Individual cells can regulate the "tightness" of the junction depending on the cells physiological and pathological demands (Tsukita et al., 2001). The tight junction complex is formed from numerous interacting proteins and include the tight-junction-associated MARVEL proteins, claudin family members and junctional adhesion molecules (JAMs). These link to the actin cytoskeleton by a cytoplasmic plaque consisting of adaptor, scaffold and signaling proteins (Zihni et al., 2016). Tight junction complexes not only confer structural integrity but also play a role in numerous signaling pathways influencing their assembly, function and polarity as well as a role in gene expression (Zihni et al., 2016).

\section{CLAUDIN PROTEIN FAMILY}

The claudin protein family are integral transcellular components of tight junctions and considered to be the main structural components of intramembrane strands (Furuse et al., 1998; Tsukita et al., 2001). Claudins are a family of 27 proteins which form the primary junctional seal through homophilic or heterophilic interactions (Mineta et al., 2011). Claudins have numerous functions helping to establish barrier properties, restricting permeability to solutes and forming charge specific pores which permit ion diffusion (Zihni et al., 2016). It is believed that the functionality of claudin proteins is specified by the extracellular loop; the tightness and ion selectivity involves the first loop whilst the second loop is important for the two opposing membranes to interact and adhere (Krause et al., 2008). Ion selectivity of each molecule across the barrier is thought to be regulated by a specific claudin protein.

Claudin expression is tissue-specific, with many cells expressing more than one family member which can be altered in response to developmental stage. Junctional "tightness" and ion selectivity arises in response to the combination and ratio of claudin members (Liebner et al., 2000; Tsukita et al., 2001). Expression of Claudins-1, -3, -5, and -12 have been reported in the brain and retinal microvasculature. However, for both vascular beds claudin-5 appears to be the most highly enriched and may indeed be the only claudin expressed at high levels (Daneman et al., 2010a; Luo et al., 2011; Vanlandewijck et al., 2018).

\section{CLAUDIN-5}

Claudin-5 is expressed specifically on endothelial cells (Morita et al., 1999b), although during embryonic development it has been shown to be transiently expressed in the retinal pigment epithelium (Kojima et al., 2002). Due to its high enrichment at the $\mathrm{BBB}$, the importance of claudin-5 in maintaining BBB function and integrity has been shown as claudin-5 null mice show a sizeselective increase (for small molecules up to $800 \mathrm{Da}$ ) in BBB permeability and are embryonic lethal, dying within a few hours of birth (Nitta et al., 2003).
Alterations in claudin-5 expression have been implicated in a number of neurological conditions including schizophrenia, depression, epilepsy and traumatic brain injury (Doherty et al., 2016; Menard et al., 2017; Greene et al., 2018, 2020; Farrell et al., 2019). In addition, claudin-5 remodeling occurs at sites of leukocyte transmigration in both physiological and pathological conditions such as Multiple Sclerosis (Paul et al., 2013; Winger et al., 2014; Castro Dias et al., 2021) and mislocalization of claudin-5 occurs in a mouse model of oxygen induced retinopathy (Luo et al., 2011). Recent work has found the inner retinal blood vessels to be highly dynamic with claudin-5 expression regulated in a circadian-manner and claudin-5 changes being a key mediator in initiating dry agerelated macular degeneration like pathology (Hudson et al., 2019). Transient modulation of claudin-5 expression using RNA interference has been shown to be beneficial in animal models of traumatic brain injury, Alzheimer's disease and choroidal neovascularization (Campbell et al., 2009, 2012; Keaney et al., 2015). This technique enabled either the removal of neurotoxic material from brain to blood or the enhanced penetration and efficacy of small molecule therapeutics into the brain or retina. Claudin-5 expression can be modulated by a number of factors including glucocorticoids, hypoxia, hormones and VEGFA (Koto et al., 2007; Argaw et al., 2009; Burek et al., 2010; Hudson et al., 2014).

\section{CLAUDIN-1}

Claudin-1 is ubiquitously expressed in most tissues of the body (Furuse et al., 1998), with a key role in skin barrier formation found as claudin-1 knockout mice die of dehydration due to the loss of the junctional barrier function to water and macromolecules (Furuse et al., 2002). The requirement of claudin-1 in tight junctions of the $\mathrm{BBB}$ is highly debated and may vary among different species. In response to pathological conditions claudin-1 expression can be altered leading to BBB disruption. Claudin-1 upregulation has been found in conditions such as stroke (Sladojevic et al., 2019), where it appears to impair interactions with other tight junction components due to its incorporation. In human glioblastoma multiforme claudin1 was found to be downregulated in tumor vessels (Liebner et al., 2000). In contrast, several groups have shown that claudin1 mRNA is not detected in brain endothelial cells (Pfeiffer et al., 2011; Vanlandewijck et al., 2018). It was found that in an animal model of multiple sclerosis, experimental autoimmune encephalomyelitis (EAE), endothelial specific inducible ectopic $\mathrm{BBB}$ expression of claudin-1 reduced $\mathrm{BBB}$ permeability and ameliorated clinical disease signs (Pfeiffer et al., 2011).

\section{CLAUDIN-3}

The role of claudin-3 in BBB integrity was first shown in studies investigating EAE and glioblastoma multiforme where loss of expression lead to a loss of BBB function (Wolburg et al., 2003). Maturation and stabilization of barrier properties 
occurred in response to $\beta$-catenin induced claudin-3 expression (Liebner et al., 2008). However recent work utilizing claudin-3 deficient mice and transcriptomic analysis found claudin-3 was not expressed in the BBB endothelium (Vanlandewijck et al., 2018; Castro Dias et al., 2019b). It has been suggested that the detection of claudin-3 at the BBB may arise due to issues with antibody specificity and cross-reactivity.

\section{CLAUDIN-12}

Claudin-12 is an atypical claudin family member which is unable to interact with the cytoskeleton due to the inability to bind to accessory adaptor proteins as it lacks a PDZ binding motif. Claudin-12 is expressed in numerous organs, and has been described to be present in the BBB (Nitta et al., 2003) and in the retina (Luo et al., 2011), although its role in the BBB tight junction complex was not fully elucidated. Recent work has found that brain claudin-12 expression is predominantly found in neurons, astrocytes and smooth muscle cells rather than the endothelium (Vanlandewijck et al., 2018; Castro Dias et al., 2019a). In addition, loss of claudin-12 did not impact $\mathrm{BBB}$ integrity under physiological or pathological inflammatory conditions such as EAE. Mice lacking claudin-12 do show some behavioral deficits including decreased locomotion and decreased anxiety, along with minor ear and retina phenotypes such as slight changes in hearing sensitivity and a reduction in axial length in the eye (Castro Dias et al., 2019a).

\section{OTHER CLAUDIN FAMILY MEMBERS}

Additional claudin family members have been suggested to be expressed at the BBB, although their cellular expression and importance in barrier integrity has not been fully characterized. This is also true for claudin expression in the retina with some family members being expressed in a developmental manner (Luo et al., 2011). Claudin-4 is integral in maintaining astrocytic tight junctions and claudin-4 degradation influences EAE development (Horng et al., 2017). Recent studies has suggested claudin- 4 to be a novel BBB tight junction component (Berndt et al., 2019), however, single cell RNA sequencing data could not detect claudin-4 expression in any brain cell types (He et al., 2018; Vanlandewijck et al., 2018). Expression of claudin-11 has been detected in a co-culture primary BBB model of endothelial cells, glial cell and pericytes (Bocsik et al., 2016) as well as in microdissected mouse and human cortical capillaries (Berndt et al., 2019). However, claudin-11 expression may appear to be more specific for oligodendrocytes localizing within the myelin rather than the tight junctions (Bronstein et al., 1996; Morita et al., 1999a; Vanlandewijck et al., 2018). Claudin-20 and -25 have also been implicated as BBB tight junction components (Berndt et al., 2019) although single cell RNA sequencing data detected claudin-20 at very low levels within capillary and arterial endothelial cells and astrocytes and claudin-25 expressed highest in oligodendrocytes (Vanlandewijck et al., 2018).

\section{TIGHT-JUNCTION-ASSOCIATED MARVEL PROTEINS}

The tight-junction-associated marvel proteins (TAMP) family of proteins include occludin, tricellulin (MARVEL D2) and MARVEL D3. Occludin was the first integral membrane protein identified to localize to tight junctions (Furuse et al., 1993) and its high expression at the $\mathrm{BBB}$ endothelium correlates with low endothelial permeability (Hirase et al., 1997). In contrast to claudin-5 null mice, mice lacking occludin are viable and do not have a deficient $\mathrm{BBB}$ due to the presence of morphologically intact tight junctions (Saitou et al., 2000; Tsukita et al., 2001). This suggests that occludin may play more of a regulatory, rather than structural, role in paracellular permeability, which can be compensated for by other tight junction proteins. The phosphorylation status of occludin is important for barriergenesis aiding in formation (Sakakibara et al., 1997), permeability (Antonetti et al., 1999; Harhaj et al., 2006) and tight junction trafficking (Murakami et al., 2009). Occludin domains exhibit distinct functions and regulatory features (Cummins, 2012). The C-terminus of occludin associates with the actin cytoskeleton via accessory proteins, such as zonula occluden (ZO)-1 (Furuse et al., 1994) and is important for paracellular permeability along with essential signaling properties. The phosphorylation status of occludin is important in disease pathology- in response to diabetes an increase in VEGF mediated phosphorylation of occludin leads to a loss of iBRB integrity and subsequent vision loss (Antonetti et al., 1998; Goncalves et al., 2021).

Tricellulin (MARVEL D2) is another transmembrane protein that is normally localized to tricellular junctions in the brain and retina (Ikenouchi et al., 2005; Iwamoto et al., 2014). However, tricellulin relocates to bicellular junctions in the absence of occludin (Ikenouchi et al., 2008). Therefore, tricellulin may have a compensatory role in the absence of occludin in the bicellular tight junction formation. Several studies have found tricellulin to be specifically enriched in brain endothelial cells (Daneman et al., 2010a; Vanlandewijck et al., 2018; Castro Dias et al., 2021). Similar to mice lacking occludin, tricellulin-deficient mice are viable although they develop hearing loss (Kitajiri et al., 2014; Kamitani et al., 2015). Under inflammatory conditions within the brain endothelium tricellulin expression is reduced leading to increased leukocyte transmigration in response to destabilization of both bi- and tricellular junctions (Castro Dias et al., 2021).

MARVEL D3 is a transmembrane protein which lacks the C-terminus found in occludin and tricellulin (Steed et al., 2009; Raleigh et al., 2010). The role of MARVEL D3 at the BBB and $\mathrm{iBRB}$ is still unknown although it has been found to be down-regulated in response to oxygen-glucose deprivation (Tornabene et al., 2019).

\section{LIPOLYSIS-STIMULATED LIPOPROTEIN RECEPTOR (LSR/ANGULIN-1)}

LSR recruits tricellulin to tricellular tight junctions (Masuda et al., 2011) and has been found to be specifically expressed in the BBB 
and iBRB (Daneman et al., 2010a; Iwamoto et al., 2014; Sohet et al., 2015). Mice deficient for LSR are embryonic lethal (Mesli et al., 2004) and show impaired barriergenesis as the BBB fails to seal and is leaky to small molecules (Sohet et al., 2015). As found for tricellulin, expression of LSR was found to be down-regulated in response to inflammation, such as EAE, and middle cerebral artery occlusion which led to destabilization of the bi- and tricellular junctions (Sohet et al., 2015; Castro Dias et al., 2021).

\section{ZONULA OCCLUDENS}

Zonula occludens $(\mathrm{ZO})$ proteins are cytoplasmic plaque proteins that form a structural link to the actin cytoskeleton and can bind to actin binding proteins including $\alpha$-catenin and cortactin (Pachter et al., 2003). ZO-1 was the first tight junction protein to be discovered in both epithelial and endothelial cells, although only the ZO-1 $\alpha^{-}$form is expressed in endothelial cells (Stevenson et al., 1986; Balda and Anderson, 1993). ZO-2 and ZO-3, have similar sequence homology to ZO-1, also localizing to tight junctions (Zihni et al., 2016), although ZO-3 is not expressed in BBB tight junctions (Inoko et al., 2003). Cells deficient for ZO$1 / 2$ fail to form tight junctions showing the importance of $\mathrm{ZO}$ proteins for tight junction assembly (Umeda et al., 2006) while ZO-1 knockout mice are embryonic lethal which is believed to be due to ZO-1 importance in endothelial tissue organization (Katsuno et al., 2008). ZO proteins have specific domains that allow for various protein-protein interactions; PDZ domains enable $\mathrm{ZO}-1$ to interact with $\mathrm{ZO}-2, \mathrm{ZO}-3$, and claudin family $\mathrm{C}$-terminus and occludin interacts via guanylate cyclase domain (Itoh et al., 1999).

In addition to tight junction complex formation, $\mathrm{ZO}-1$ and ZO-2 have a role in gene transcription regulating transcription factors as well as cell proliferation via its ability to bind $\mathrm{ZO}$ 1 -associated nucleic acid binding (ZONAB) (Balda and Matter, 2009). Accumulation of ZONAB in the nucleus occurs when cell density is low, but if cell density is high ZONAB interacts with ZO-1 at cellular junctions (Balda and Matter, 2000; Balda et al., 2003). ZO-1 has also been found to mediate a role in endothelial cell-cell tension, cell migration and angiogenesis (Tornavaca et al., 2015). Like claudin-5 and occludin, ZO-1 expression is reduced in certain neurological diseases leading to barrier instability.

\section{JUNCTIONAL ADHESION MOLECULES}

JAMs are single span members of the immunoglobulin superfamily (Martì-Padura et al., 1998) that are important for tight junction assembly and integrity (Ebnet, 2017). There are three family members JAM-A, $-\mathrm{B}$, and $-\mathrm{C}$ which can all interact with PAR-3, a core component of the cellular polarity regulating machinery which localizes to tight junctions (Ebnet, 2017). All three JAMs have the capacity to interact with ZO1, while JAM-A can also regulate the localization of ZO-1 within the junction complex. JAM-A is the predominant isoform in the brain and retinal endothelium regulating permeability changes (Aurrand-Lions et al., 2001; Tomi and Hosoya, 2004). Furthermore, JAM-A and JAM-C have been implicated in leukocyte trafficking as well as junction integrity (Woodfin et al., 2007, 2011; Williams et al., 2015; Hou et al., 2021). JAM-C has been shown to play a specific role in regulating microvascular permeability during inflammation by targeting the adherens junction protein vascular endothelial cadherin which can regulate claudin-5 expression via a $\beta$-catenin and FoxO1 dependent pathway (Taddei et al., 2008).

Endothelial selective cell adhesion molecule (ESAM) has a similar structure to JAM proteins. ESAM localization is supported by its interaction with ZO-1 in the brain capillaries (Nasdala et al., 2002) and it plays a role in endothelial cell-cell interaction during vascular development and neutrophil extravasation during early stages of inflammation (Wegmann et al., 2004).

\section{CONCLUSION}

Tight junctions found in the $\mathrm{BBB}$ and $\mathrm{BBRB}$ are complex and dynamic in nature, comprising numerous interacting proteins that aid in the gate and fence function. The contribution of other cell types found in the NVU, astrocytes, pericytes, and microglia/macrophages as well as the presence of the basement membrane are essential in ensuring the highly specialized barrier properties. All components are integral in maintaining a homeostatic balance and the integrity of the brain and retina in both healthy and disease states. Of particular importance in maintaining $\mathrm{BBB}$ and $\mathrm{BBRB}$ integrity is claudin-5, the most highly enriched tight junction component which when dysregulated has been linked to a number of neurodegenerative pathologies. In recent years the involvement of claudin-1, -3 , and -12 in $\mathrm{BBB}$ integrity and function has come into dispute as these claudin family members are found to be expressed at extremely low levels in the brain endothelium.

\section{AUTHOR CONTRIBUTIONS}

$\mathrm{NH}$ and $\mathrm{MC}$ wrote the manuscript. Both authors contributed to the article and approved the submitted version.

\section{FUNDING}

This work was supported by the grants from Science Foundation Ireland (SFI), (12/YI/B2614 and 11/PI/1080), the Irish Research Council (IRC), The Health Research Board of Ireland (HRB), the BrightFocus Foundation. The Campbell lab at TCD was also supported by the SFI Centres grant supported in part by a research grant from SFI under grant no. 16/RC/3948 and co-funded under the European Regional Development fund by FutureNeuro industry partners. The Campbell lab was also supported by a European Research Council (ERC) grant, "RetinaRhythm" (864522). 


\section{REFERENCES}

Abbott, N. J., Ronnback, L., and Hansson, E. (2006). Astrocyte-endothelial interactions at the blood-brain barrier. Nat. Rev. Neurosci. 7, 41-53. doi: 10 . 1038/nrn1824

Antonetti, D. A., Barber, A. J., Hollinger, L. A., Wolpert, E. B., and Gardner, T. W. (1999). Vascular endothelial growth factor induces rapid phosphorylation of tight junction proteins occludin and zonula occluden 1 . A potential mechanism for vascular permeability in diabetic retinopathy and tumors. J. Biol. Chem. 274, 23463-23467. doi: 10.1074/jbc.274.33.23463

Antonetti, D. A., Barber, A. J., Khin, S., Lieth, E., Tarball, J. M., and Gardner, T. W. (1998). Vascular permeability in experimental diabetes is associated with reduced endothelial occludin content: vascular endothelial growth factor decreases occludin in retinal endothelial cells. Penn State Retina Research Group. Diabetes 47, 1953-1959. doi: 10.2337/diabetes.47.12.1953

Argaw, A. T., Gurfein, B. T., Zhang, Y., Zameer, A., and John, G. R. (2009). VEGF-mediated disruption of endothelial CLN-5 promotes blood-brain barrier breakdown. Proc. Natl. Acad. Sci. U. S. A. 106, 1977-1982. doi: 10.1073/pnas. 0808698106

Armulik, A., Genové, G., Mäe, M., Nisancioglu, M. H., Wallgard, E., Niaudet, C., et al. (2010). Pericytes regulate the blood brain barrier. Nature 468, 557-561.

Aurrand-Lions, M., Duncan, L., Ballestrem, C., and Imhof, B. A. (2001). JAM-2, a novel immunoglobulin superfamily molecule, expressed by endothelial and lymphatic cells. J. Biol. Chem. 276, 2733-2741. doi: 10.1074/jbc.m005458200

Balda, M. S., and Anderson, J. M. (1993). Two classes of tight junctions are revealed by ZO-1 isoforms. Am. J. Physiol. 264, C918-C924. doi: 10.1152/ajpcell.1993. 264.4.C918

Balda, M. S., Garrett, M. D., and Matter, K. (2003). The ZO-1-associated Y-box factor ZONAB regulates epithelial cell proliferation and cell density. J. Cell Biol. 160, 423-432. doi: 10.1083/jcb.200210020

Balda, M. S., and Matter, K. (2000). The tight junction protein ZO-1 and an interacting transcription factor regulate ErbB-2 expression. EMBO J. 19, 20242033. doi: $10.1093 /$ emboj/19.9.2024

Balda, M. S., and Matter, K. (2009). Tight junctions and the regulation of gene expression. Biochim. Biophys. Acta 1788, 761-767. doi: 10.1016/j.bbamem. 2008.11.024

Berndt, P., Winkler, L., Cording, J., Breitkreuz-Korff, O., Rex, A., Dithmer, S., et al. (2019). Tight junction proteins at the blood-brain barrier: far more than claudin-5. Cell. Mol. Life Sci. 76, 1987-2002. doi: 10.1007/s00018-019-03030-7

Bocsik, A., Walter, F. R., Gyebrovszki, A., Fülöp, L., Blasig, I., Dabrowski, S., et al. (2016). Reversible Opening of Intercellular Junctions of Intestinal Epithelial and Brain Endothelial Cells With Tight Junction Modulator Peptides. J. Pharm. Sci. 105, 754-765. doi: 10.1016/j.xphs.2015.11.018

Bronstein, J. M., Popper, P., Micevych, P. E., and Farber, D. B. (1996). Isolation and characterization of a novel oligodendrocyte-specific protein. Neurology 47, 772-778. doi: 10.1212/wnl.47.3.772

Burek, M., Arias-Loza, P. A., Roewer, N., and Förster, C. Y. (2010). Claudin-5 as a novel estrogen target in vascular endothelium. Arterioscler. Thromb. Vasc. Biol. 30, 298-304. doi: 10.1161/ATVBAHA.109.197582

Campbell, M., Hanrahan, F., Gobbo, O. L., Kelly, M. E., Kiang, A. S., Humphries, M. M., et al. (2012). Targeted suppression of claudin-5 decreases cerebral oedema and improves cognitive outcome following traumatic brain injury. Nat. Commun. 3:849. doi: 10.1038/ncomms 1852

Campbell, M., Nguyen, A. T., Kiang, A. S., Tam, L. C. S., Gobbo, O. L., Kerskens, C., et al. (2009). An experimental platform for systemic drug delivery to the retina. Proc. Natl. Acad. Sci. U. S. A. 106, 17817-17822. doi: 10.1073/pnas.0908561106

Castro Dias, M, Quesada, A. O., Soldati, S., Bösch, F., Gruber, I., and Hildbrand, T. (2021). Brain endothelial tricellular junctions as novel sites for T cell diapedesis across the blood-brain barrier. J. Cell Sci. 134:jcs253880. doi: 10.1242/jcs. 253880

Castro Dias, M., Coisne, C., Lazarevic, I., Baden, P., Hata, M., Iwamoto, N., et al. (2019b). Claudin-3-deficient C57BL/6J mice display intact brain barriers. Sci. Rep. 9:203.

Castro Dias, M., Coisne, C., Baden, P., Enzmann, G., Garrett, L., Becker, L., et al. (2019a). Claudin-12 is not required for blood-brain barrier tight junction function. Fluids Barriers CNS 16:30.

Cummins, P. M. (2012). Occludin: one protein, many forms. Mol. Cell Biol. 32, 242-250.
Daneman, R., Zhou, L., Kebede, A. A., and Barres, B. A. (2010b). Pericytes are required for blood-brain barrier integrity during embryogenesis. Nature 468, 562-566. doi: 10.1038/nature09513

Daneman, R., Zhou, L., Agalliu, D., Cahoy, J. D., Kaushal, A., and Barres, B. A. (2010a). The mouse blood-brain barrier transcriptome: a new resource for understanding the development and function of brain endothelial cells. PLoS One 5:e13741. doi: 10.1371/journal.pone.0013741

Doherty, C. P., O’Keefe, E., Wallace, E., Loftus, T., Keaney, J., Kealy, J., et al. (2016). Blood-Brain Barrier Dysfunction as a Hallmark Pathology in Chronic Traumatic Encephalopathy. J. Neuropathol. Exp. Neurol. 75, 656-662.

Ebnet, K. (2017). Junctional Adhesion Molecules (JAMs): cell Adhesion Receptors With Pleiotropic Functions in Cell Physiology and Development. Physiol. Rev. 97, 1529-1554. doi: 10.1152/physrev.00004.2017

Enge, M., Bjarnegard, M., Gerhardt, H., Gustafsson, E., Kalen, M., Asker, N., et al. (2002). Endothelium-specific platelet-derived growth factor-B ablation mimics diabetic retinopathy. EMBO J. 21, 4307-4316. doi: 10.1093/emboj/cdf418

Farrell, M., Aherne, S., O’Riordan, S., O'Keeffe, E., Greene, C., and Campbell, M. (2019). Blood-brain barrier dysfunction in a boxer with chronic traumatic encephalopathy and schizophrenia. Clin. Neuropathol. 38, 51-58. doi: 10.5414/ NP301130

Frank, R. N., Turczyn, T. J., and Das, A. (1990). Pericyte coverage of retinal and cerebral capillaries. Invest. Ophthalmol. Vis. Sci. 31, 999-1007.

Furuse, M., Fujita, K., Hiiragi, T., Fujimoto, K., and Tsukita, S. (1998). Claudin-1 and -2 : novel integral membrane proteins localizing at tight junctions with no sequence similarity to occludin. J. Cell Biol. 141, 1539-1550. doi: 10.1083/jcb. 141.7.1539

Furuse, M., Hata, M., Furuse, K., Yoshida, Y., Haratake, A., Sugitani, Y., et al. (2002). Claudin-based tight junctions are crucial for the mammalian epidermal barrier: a lesson from claudin-1-deficient mice. J. Cell Biol. 156, 1099-1111. doi: $10.1083 /$ jcb.200110122

Furuse, M., Hirase, T., Itoh, M., Nagafuchi, A., Yonemura, S., Tsukita, S., et al. (1993). Occludin: a novel integral membrane protein localizing at tight junctions. J. Cell Biol. 123, 1777-1788. doi: 10.1083/jcb.123.6.1777

Furuse, M., Itoh, M., Hirase, T., Nagafuchi, A., Yonemura, S., Tsukita, S., et al. (1994). Direct association of occludin with ZO-1 and its possible involvement in the localization of occludin at tight junctions. J. Cell Biol. 127, 1617-1626. doi: $10.1083 /$ jcb.127.6.1617

Goncalves, A., Dreffs, A., Lin, C. M., Sheskey, S., Hudson, N., Keil, J., et al. (2021). Vascular Expression of Permeability-Resistant Occludin Mutant Preserves Visual Function in Diabetes. Diabetes 70, 1549-1560. doi: 10.2337/db20-1220

Greene, C., Hanley, N., and Campbell, M. (2020). Blood-brain barrier associated tight junction disruption is a hallmark feature of major psychiatric disorders. Transl. Psychiatry 10:373. doi: 10.1038/s41398-020-01054-3

Greene, C., Kealy, J., Humphries, M. M., Gong, Y., Hou, J., Hudson, N., et al. (2018). Dose-dependent expression of claudin-5 is a modifying factor in schizophrenia. Mol. Psychiatry 23, 2156-2166. doi: 10.1038/mp.2017.156

Hallmann, R., Hannocks, M. J., Song, J., Zhang, X., Di Russo, J., Luik, A. L., et al. (2020). The role of the basement membrane laminins in vascular function. Int. J. Biochem. Cell Biol. 127:105823. doi: 10.1016/j.biocel.2020.105823

Hamilton, N. B., Atwell, D., and Hall, C. N. (2010). Pericyte-mediated regulation of capillary diameter: a component of neurovascular coupling in health and disease. Front. Neuroenergetics 2:5. doi: 10.3389/fnene.2010.00005

Harhaj, N. S., Felinski, E. A., Wolpert, E. B., Sundstrom, J. M., Gardner, T. W., and Antonetti, D. (2006). VEGF activation of protein kinase C stimulates occludin phosphorylation and contributes to endothelial permeability. Invest. Ophthalmol. Vis. Sci. 47, 5106-5115.

He, L., Vanlandewijck, M., Mäe, M. A., Andrae, J., Ando, K., Del Gaudio, F., et al. (2018). Single-cell RNA sequencing of mouse brain and lung vascular and vessel-associated cell types. Sci. Data 5:180160. doi: 10.1038/sdata.2018.160

Hirase, T., Staddon, J. M., Saitou, M., Ando-Akatsuka, Y., Itoh, M., Furuse, M., et al. (1997). Occludin as a possible determinant of tight junction permeability in endothelial cells. J. Cell Sci. 110, 1603-1613. doi: 10.1242/jcs.110.14.1603

Hori, S., Ohtsuki, S., Hosoya, K., Nakashima, E., and Terasaki, T. (2004). A pericyte-derived angiopoietin-1 multimeric complex induces occludin gene expression in brain capillary endothelial cells through Tie-2 activation in vitro. J. Neurochem. 89, 503-513. doi: 10.1111/j.1471-4159.2004.02343.x

Horng, S., Therattil, A., Moyon, S., Gordon, A., Kim, K., Argaw, A. T., et al. (2017). Astrocytic tight junctions control inflammatory CNS 
lesion pathogenesis. J. Clin. Invest. 127, 3136-3151. doi: 10.1172/JCI9 1301

Hou, X., Du, H. J., Zhou, J., Hu, D., Wang, Y. S., and Li, X. (2021). Role of Junctional Adhesion Molecule C in the Regulation of Inner Endothelial Blood-Retinal Barrier Function. Front. Cell Dev. Biol. 9:695657. doi: 10.3389/fcell.2021.695657

Hudson, N., and Campbell, M. (2019). Inner Blood-Retinal Barrier Regulation in Retinopathies. Adv. Exp. Med. Biol. 1185, 329-333. doi: 10.1007/978-3-03027378-1_54

Hudson, N., Celkova, L., Hopkins, A., Greene, C., Storti, F., Ozaki, E., et al. (2019). Dysregulated claudin-5 cycling in the inner retina causes retinal pigment epithelial cell atrophy. JCI Insight 4:e130273. doi: 10.1172/jci.insight.130273

Hudson, N., Powner, M. B., Sarker, M. H., Burgoyne, T., Campbell, M., Ockrim, Z. K., et al. (2014). Differential apicobasal VEGF signaling at vascular bloodneural barriers. Dev. Cell 30, 541-552. doi: 10.1016/j.devcel.2014.06.027

Ikenouchi, J., Furuse, M., Furuse, K., Sasaki, H., Tsukita, S., and Tsukita, S. (2005). Tricellulin constitutes a novel barrier at tricellular contacts of epithelial cells. J. Cell Biol. 171, 939-945. doi: 10.1083/jcb.200510043

Ikenouchi, J., Sasaki, H., Tsukita, S., Furuse, M., and Tsukita, S. (2008). Loss of occludin affects tricellular localization of tricellulin. Mol. Biol. Cell 19, 4687-4693. doi: 10.1091/mbc.e08-05-0530

Inoko, A., Itoh, M., Tamura, A., Matsuda, M., Furuse, M., and Tsukita, S. (2003). Expression and distribution of ZO-3, a tight junction MAGUK protein, in mouse tissues. Genes Cells 8, 837-845. doi: 10.1046/j.1365-2443.2003.00681.x

Itoh, M., Furuse, M., Morita, K., Kubota, K., Saitou, M., and Tsukita, S. (1999). Direct binding of three tight junction-associated MAGUKs, ZO-1, ZO-2, and ZO-3, with the COOH termini of claudins. J. Cell Biol. 147, 1351-1363. doi: 10.1083/jcb.147.6.1351

Iwamoto, N., Higashi, T., and Furuse, M. (2014). Localization of angulin-1/LSR and tricellulin at tricellular contacts of brain and retinal endothelial cells in vivo. Cell Struct. Funct. 39, 1-8. doi: 10.1247/csf.13015

Kamitani, T., Sakaguchi, H., Tamura, A., Miyashita, T., Yamazaki, Y., Tokumasu, R., et al. (2015). Deletion of Tricellulin Causes Progressive Hearing Loss Associated with Degeneration of Cochlear Hair Cells. Sci. Rep. 5:18402. doi: 10.1038 /srep 18402

Katsuno, T., Umeda, K., Matsui, T., Hata, M., Tamura, A., Itoh, M., et al. (2008). Deficiency of zonula occludens- 1 causes embryonic lethal phenotype associated with defected yolk sac angiogenesis and apoptosis of embryonic cells. Mol. Biol. Cell 19, 2465-2475. doi: 10.1091/mbc.e07-12-1215

Keaney, J., Walsh, D. M., O’Malley, T., Hudson, N., Crosbie, D. E., Loftus, T., et al. (2015). Autoregulated paracellular clearance of amyloid- $\beta$ across the blood-brain barrier. Sci. Adv. 1:e1500472. doi: 10.1126/sciadv.1500472

Kitajiri, S., Katsuno, T., Sasaki, H., Ito, J., Furuse, M., and Tsukita, S. (2014). Deafness in occludin-deficient mice with dislocation of tricellulin and progressive apoptosis of the hair cells. Biol. Open 3, 759-766. doi: 10.1242/bio. 20147799

Kojima, S., Rahner, C., Peng, S., and Rizzolo, L. J. (2002). Claudin 5 is transiently expressed during the development of the retinal pigment epithelium. J. Membr. Biol. 186, 81-88. doi: 10.1007/s00232-001-0137-7

Koto, T., Takubo, K., Ishida, S., Shinoda, H., Inoue, M., Tsubota, K., et al. (2007). Hypoxia disrupts the barrier function of neural blood vessels through changes in the expression of claudin-5 in endothelial cells. Am. J. Pathol. 170, 1389-1397. doi: 10.2353/ajpath.2007.060693

Krause, G., Winkler, L., Mueller, S. L., Haseloff, R. F., Piontek, J., and Blasig, I. E. (2008). Structure and function of claudins. Biochim. Biophys. Acta 1778, 631-645. doi: 10.1016/j.bbamem.2007.10.018

Lapenna, A., De Palma, M., and Lewis, C. E. (2018). Perivascular macrophages in health and disease. Nat. Rev. Immunol. 18, 689-702. doi: 10.1038/s41577-0180056-9

Lendahl, U., Nilsson, P., and Betsholtz, C. (2019). Emerging links between cerebrovascular and neurodegenerative diseases- a special role for pericytes. EMBO Rep. 20:e48070. doi: 10.15252/embr.201948070

Liebner, S., Corada, M., Bangsow, T., Babbage, J., Taddei, A., Czupalla, C. J., et al. (2008). Wnt/beta-catenin signaling controls development of the blood-brain barrier. J. Cell Biol. 183, 409-417. doi: 10.1083/jcb.200806024

Liebner, S., Fischmann, A., Rascher, G., Duffner, F., Grote, E. H., Kalbacher, H., et al. (2000). Claudin-1 and claudin-5 expression and tight junction morphology are altered in blood vessels of human glioblastoma multiforme. Acta Neuropathol. 100, 323-331. doi: 10.1007/s004010000180
Luo, Y., Xiao, W., Zhu, X., Mao, Y., Liu, X., Huang, J., et al. (2011). Differential expression of claudins in retinas during normal development and the angiogenesis of oxygen-induced retinopathy. Invest. Ophthalmol. Vis. Sci. 52, 7556-7564. doi: 10.1167/iovs.11-7185

Martìn-Padura, I., Lostaglio, S., Schneemann, M., Williams, L., Romano, M., Fruscella, P., et al. (1998). Junctional adhesion molecule, a novel member of the immunoglobulin superfamily that distributes at intercellular junctions and modulates monocyte transmigration. J. Cell Biol. 142, 117-127. doi: 10.1083/ jcb.142.1.117

Masuda, S., Oda, Y., Sasaki, H., Ikenouchi, J., Higashi, T., Akashi, M., et al. (2011). LSR defines cell corners for tricellular tight junction formation in epithelial cells. J. Cell Sci. 124, 548-555. doi: 10.1242/jcs.072058

Menard, C., Pfau, M. L., Hodes, G. E., Kana, V., Wang, V. X., Bouchard, S., et al. (2017). Social stress induces neurovascular pathology promoting depression. Nat. Neurosci. 20, 1752-1760.

Mesli, S., Javorschi, S., Bérard, A. M., Landry, M., Priddle, H., Kivlichan, D., et al. (2004). Distribution of the lipolysis stimulated receptor in adult and embryonic murine tissues and lethality of LSR-/- embryos at 12.5 to 14.5 days of gestation. Eur. J. Biochem. 271, 3103-3114. doi: 10.1111/j.1432-1033.2004.04223.x

Mineta, K., Yamamoto, Y., Yamazaki, Y., Tanaka, H., Tada, Y., Saitou, K., et al. (2011). Predicted expansion of the claudin multigene family. FEBS Lett. 585, 606-612. doi: 10.1016/j.febslet.2011.01.028

Miyagoe, Y., Hanaoka, K., Nonaka, I., Hayasaka, M., Nabeshima, Y., Arahata, K., et al. (1997). Laminin alpha2 chain-null mutant mice by targeted disruption of the Lama2 gene: a new model of merosin (laminin 2)-deficient congenital muscular dystrophy. FEBS Lett. 415, 33-39. doi: 10.1016/s0014-5793(97) 01007-7

Morita, K., Sasaki, H., Furuse, M., and Tsukita, S. (1999b). Endothelial claudin: claudin-5/TMVCF constitutes tight junction strands in endothelial cells. J. Cell Biol. 147, 185-194. doi: 10.1083/jcb.147.1.185

Morita, K., Sasaki, H., Fujimoto, K., Furuse, M., and Tsukita, S. (1999a). Claudin$11 /$ OSP-based tight junctions of myelin sheaths in brain and Sertoli cells in testis. J. Cell Biol. 145, 579-588. doi: 10.1083/jcb.145.3.579

Murakami, T., Felinski, E. A., and Antonetti, D. A. (2009). Occludin phosphorylation and ubiquitination regulate tight junction trafficking and vascular endothelial growth factor-induced permeability. J. Biol. Chem. 284, 21036-21046. doi: 10.1074/jbc.m109.016766

Nasdala, I., Wolburg-Buchholz, K., Wolburg, H., Kuhn, A., Ebnet, K., Brachtendorf, G., et al. (2002). A transmembrane tight junction protein selectively expressed on endothelial cells and platelets. J. Biol. Chem. 277, 16294-16303.

Nitta, T., Hata, M., Gotoh, S., Seo, Y., Sasaki, H., Hashimoto, N., et al. (2003). Sizeselective loosening of the blood-brain barrier in claudin-5-deficient mice. J. Cell Biol. 161, 653-660. doi: 10.1083/jcb.200302070

Otani, T., and Furuse, M. (2020). Tight Junction Structure and Function Revisited. Trends Cell Biol. 30, 805-817.

Pachter, J. S., de Vries, H. E., and Fabry, Z. (2003). The blood-brain barrier and its role in immune privilege in the central nervous system. J. Neuropathol. Exp. Neurol. 62, 593-604.

Park, D. Y., Lee, J., Kim, J., Kim, K., Hong, S., Han, S., et al. (2017). Plastic roles of pericytes in the blood-retinal barrier. Nat. Commun. 8:15296. doi: 10.1038/ncomms15296

Paul, D., Cowan, A. E., Ge, S., and Pachter, J. S. (2013). Novel 3D analysis of Claudin-5 reveals significant endothelial heterogeneity among CNS microvessels. Microvasc. Res. 86, 1-10. doi: 10.1016/j.mvr.2012.12.001

Peppiatt, C. M., Howarth, C., Mobbs, P., and Atwell, D. (2006). Bidirectional control of CNS capillary diameter by pericytes. Nature 443, 700-704. doi: 10.1038 /nature05193

Perry, V. H., Nicoll, J. A., and Holmes, C. (2010). Microglia in neurodegenerative disease. Nat. Rev. Neurol. 6, 193-201.

Pfeiffer, F., Schäfer, J., Lyck, R., Makrides, V., Brunner, S., Schaeren-Wiemers, N., et al. (2011). Claudin-1 induced sealing of blood-brain barrier tight junctions ameliorates chronic experimental autoimmune encephalomyelitis. Acta Neuropathol. 122, 601-614. doi: 10.1007/s00401-011-0883-2

Poschl, E., Schlotzer-Schrehardt, U., Brachvogel, B., Saito, K., Ninomiya, Y., and Mayer, U. (2004). Collagen IV is essential for basement membrane stability but dispensable for initiation of its assembly during early development. Development 131, 1619-1628. doi: 10.1242/dev.01037 
Raleigh, D. R., Marchiando, A. M., Zhang, Y., Shen, L., Sasaki, H., Wang, Y., et al. (2010). Tight Junction-associated MARVEL Proteins MarvelD3, Tricellulin, and Occludin Have Distinct but Overlapping Functions. Mol. Biol. Cell 21, 1200-1213. doi: 10.1091/mbc.e09-08-0734

Reichenbach, A., and Bringmann, A. (2020). Glia of the human retina. Glia 68, 768-796.

Ronaldson, P. T., and Davis, T. P. (2020). Regulation of blood-brain barrier integrity by microglia in health and disease: a therapeutic opportunity. J. Cereb. Blood Flow Metab. 40, S6-S24. doi: 10.1177/0271678X20951995

Saitou, M., Furuse, M., Sasaki, H., Schulzke, J. D., Fromm, M., Takano, T., et al. (2000). Complex phenotype of mice lacking occludin, a component of tight junction strands. Mol. Biol. Cell 11, 4131-4142. doi: 10.1091/mbc.11.12. 4131

Sakakibara, A., Furuse, M., Saitou, M., Ando-Akatsuka, Y., and Tsukita, S. (1997). Possible involvement of phosphorylation of occludin in tight junction formation. J. Cell Biol. 137, 1393-1401.

Sarrazin, S., Lamanna, W. C., and Esko, J. D. (2011). Heparan sulfate proteoglycans. Cold Spring Harb. Perspect. Biol. 3:a004952.

Segarra, M., Aburto, M. R., Cop, F., Llaó-Cid, C., Härtl, R., Damm, M., et al. (2018). Endothelial Dab1 signaling orchestrates neuro-glia-vessel communication in the central nervous system. Science 361:eaao2861. doi: 10.1126/science.aao2861

Sladojevic, N., Stamatovic, S. M., Johnson, A. M., Choi, J., Hu, A., Dithmer, S., et al. (2019). Claudin-1-Dependent Destabilization of the Blood-Brain Barrier in Chronic Stroke. J. Neurosci. 39, 743-757. doi: 10.1523/JNEUROSCI.143218.2018

Sohet, F., Lin, C., Munji, R. N., Lee, S. Y., Ruderisch, N., Soung, A., et al. (2015). LSR/angulin-1 is a tricellular tight junction protein involved in blood-brain barrier formation. J. Cell Biol. 208, 703-711. doi: 10.1083/jcb.201410131

Steed, E., Rodrigues, N. T. L., Balda, M. S., and Matter, K. (2009). Identification of MarvelD3 as a tight junction-associated transmembrane protein of the occludin family. BMC Cell Biol. 10:95. doi: 10.1186/1471-2121-10-95

Stevenson, B. R., Siliciano, J. D., Mooseker, M. S., and Goodenough, D. A. (1986). Identification of ZO-1: a high molecular weight polypeptide associated with the tight junction (zonula occludens) in a variety of epithelia. J. Cell Biol. 103, 755-766. doi: $10.1083 /$ jcb.103.3.755

Taddei, A., Giampietro, C., Conti, A., Orsenigo, F., Breviario, F., Pirazzoli, V., et al. (2008). Endothelial adherens junctions control tight junctions by VEcadherin-mediated upregulation of claudin-5. Nat. Cell Biol. 10, 923-934. doi: $10.1038 /$ ncb 1752

Thomsen, M. S., Routhe, L. J., and Moos, T. (2017). The vascular basement membrane in the healthy and pathological brain. J. Cereb. Blood Flow Metab. 37, 3300-3317. doi: 10.1177/0271678x17722436

Tomi, M., and Hosoya, K. J. (2004). Application of magnetically isolated rat retinal vascular endothelial cells for the determination of transporter gene expression levels at the inner blood-retinal barrier. Neurochem 91, 1244-1248. doi: 10 . 1111/j.1471-4159.2004.02842.x

Tornabene, E., Helms, H. C. C., Pedersen, S. F., and Brodin, B. (2019). Effects of oxygen-glucose deprivation (OGD) on barrier properties and mRNA transcript levels of selected marker proteins in brain endothelial cells/astrocyte cocultures. PLoS One 14:e0221103. doi: 10.1371/journal.pone.0221103

Tornavaca, O., Chia, M., Dufton, N., Almagro, L. O., Conway, D. E., Randi, A. M., et al. (2015). ZO-1 controls endothelial adherens junctions, cell-cell tension, angiogenesis, and barrier formation. J. Cell Biol. 208, 821-838. doi: 10.1083/ jcb. 201404140

Tsukita, S., Furuse, M., and Itoh, M. (2001). Multifunctional strands in tight junctions. Nat. Rev. Mol. Cell Biol. 2, 285-293. doi: 10.1038/35067088

Umeda, K., Ikenouchi, J., Katahira-Tayama, S., Furuse, K., Sasaki, H., Nakayama, M., et al. (2006). ZO-1 and ZO-2 independently determine where claudins are polymerized in tight-junction strand formation. Cell 126, 741-754. doi: 10.1016/j.cell.2006.06.043

Vanlandewijck, M., He, L., Mäe, M. A., Andrae, J., Ando, K., Del Gaudio, F., et al. (2018). A molecular atlas of cell types and zonation in the brain vasculature. Nature 554, 475-480. doi: 10.1038/nature25739

Wegmann, F., Ebnet, K., Du Pasquier, L., Vestweber, D., and Butz, S. (2004). Endothelial adhesion molecule ESAM binds directly to the multidomain adaptor MAGI-1 and recruits it to cell contacts. Exp. Cell Res. 300, 121-133. doi: 10.1016/j.yexcr.2004.07.010

Williams, D. W., Anastos, K., Morgello, S., and Berman, J. W. (2015). JAM$A$ and ALCAM are therapeutic targets to inhibit diapedesis across the BBB of CD14+CD16+ monocytes in HIV-infected individuals. J. Leukoc. Biol. 97, 401-412.

Winger, R. C., Koblinski, J. E., Kanda, T., Ransohoff, R. M., and Muller, W. A. (2014). Rapid remodeling of tight junctions during paracellular diapedesis in a human model of the blood-brain barrier. J. Immunol. 193, 2427-2437. doi: 10.4049/jimmunol.1400700

Wolburg, H., Wolburg-Buchholz, K., Kraus, J., Rascher-Eggstein, G., Liebner, S., Hamm, S., et al. (2003). Localization of claudin-3 in tight junctions of the blood-brain barrier is selectively lost during experimental autoimmune encephalomyelitis and human glioblastoma multiforme. Acta Neuropathol. 105, 586-592. doi: 10.1007/s00401-003-0688-z

Woodfin, A., Reichel, C. A., Khandoga, A., Corada, M., Voisin, M. B., Scheiermann, C., et al. (2007). JAM-A mediates neutrophil transmigration in a stimulusspecific manner in vivo: evidence for sequential roles for JAM-A and PECAM-1 in neutrophil transmigration. Blood 110, 1848-1856. doi: 10.1182/blood-200609-047431

Woodfin, A., Voisin, M. B., Beyrau, M., Colom, B., Caille, D., Diapouli, F. M., et al. (2011). The junctional adhesion molecule-C (JAM-C) regulates polarized neutrophil transendothelial cell migration in vivo. Nat. Immunol. 12, 761-769. doi: $10.1038 /$ ni.2062

Wu, C., Ivars, F., Anderson, P., Hallmann, R., Vestweber, D., Nilsson, P., et al. (2009). Endothelial basement membrane laminin $\alpha 5$ selectively inhibits $\mathrm{T}$ lymphocyte extravasation into the brain. Nat. Med. 15, 519-527. doi: 10.1038/ nm.1957

Yao, Y., Chin, Z.-L., Norris, E. H., and Strickland, S. (2014). Astrocytic laminin regulates pericyte differentiation and maintains blood brain barrier integrity. Nat. Commun. 5:3413. doi: 10.1038/ncomms4413

Zihni, C., Mills, C., Matter, K., and Balda, M. S. (2016). Tight junctions: from simple barriers to multifunctional molecular gates. Nat. Rev. Mol. Cell Biol. 17, 564-580. doi: 10.1038/nrm.2016.80

Conflict of Interest: The authors declare that the research was conducted in the absence of any commercial or financial relationships that could be construed as a potential conflict of interest.

Publisher's Note: All claims expressed in this article are solely those of the authors and do not necessarily represent those of their affiliated organizations, or those of the publisher, the editors and the reviewers. Any product that may be evaluated in this article, or claim that may be made by its manufacturer, is not guaranteed or endorsed by the publisher.

Copyright (C) 2021 Hudson and Campbell. This is an open-access article distributed under the terms of the Creative Commons Attribution License (CC BY). The use, distribution or reproduction in other forums is permitted, provided the original author(s) and the copyright owner(s) are credited and that the original publication in this journal is cited, in accordance with accepted academic practice. No use, distribution or reproduction is permitted which does not comply with these terms. 